\title{
Propriedades psicométricas das escalas de assédio moral no trabalho - percepção e impacto
}

\author{
Maria do Carmo Fernandes Martins' - Universidade Metodista de São Paulo, São Bernardo do Campo, Brasil \\ Ana Maria Souto Ferraz - Universidade Federal de Uberlândia, Uberlândia, Brasil
}

\begin{abstract}
Resumo
Este texto relata a adaptação e as características psicométricas de medidas de assédio moral no trabalho: a Escala de Percepção da Frequência e a Escala de Impacto Afetivo do Assédio Moral no Trabalho. Os instrumentos, autoaplicáveis, possuíam itens idênticos, mas foram respondidos em escalas diferentes, uma referindo-se à percepção de assédio e outra, ao impacto afetivo provocado pelo fenômeno. Participaram 216 trabalhadores, ocupantes de funções diversas, como atividades de apoio administrativo, assistência à saúde, serviços gerais, de atendimento e recepção de pessoas, policiais militares, de vendas e professores. Possuíam idades entre 17 e 61 anos; 65\% eram mulheres. Resultados das análises fatoriais revelaram dois fatores componentes da Escala de Percepção do Assédio Moral no Trabalho, mas apenas fator um compôs a Escala de Impacto Afetivo do Assédio Moral. Indicadores satisfatórios de consistência interna indicavam que todos os itens contribuíram para melhorar a fidedignidade das escalas. A estrutura encontrada diferiu da relatada na literatura e estes achados embasam a discussão dos resultados.

Palavras-chave: Assédio moral no trabalho, Validade, Fidedignidade, Escala.
\end{abstract}

\section{Psychometric properties of psychological harassment scales at work - perception and impact}

\begin{abstract}
This text reports the adaptation and psychometric characteristics of psychological harassment measures: the frequency perception and the affective impact harassment scales. The instruments -self-applicable- had identical items, but were answered in different scales; one referring to the harassment perception and the other, to the affective impact caused by the phenomenon. 216 workers participated, who occupy diverse positions, like administrative support activities, health assistance, general services, people servicing and reception, military officers, sales and teachers. They were between 17 and 61 years-old, and 65\% was female. Factorial analysis results revealed two Harassment Perception Scale factors, but only one of them was revealed in the Harassment Affective Impact Scale. Satisfactory internal consistency indicators pointed out that all the items contributed to improve scales reliability. The structure found differed from that related in literature, and such results are the basis of results discussion.
\end{abstract}

Keywords: Psychological harassment, Validity, Reliability, Scale.

Assédio moral no trabalho pode ser definido como um fenômeno manifestado por violência psicológica extrema, exercida de maneira sistemática e recorrente por uma pessoa ou por grupo de pessoas sobre outra no local de trabalho (Leymann, 1990). Revisão bibliográfica realizada para este estudo revelou um estado de consolidação do construto, mas mostrou ainda certas inconclusões sobre o conceito.

Para Heloani (2004), a precariedade e a seletividade de trabalho favorecem a competição entre trabalhadores, mas, ao mesmo tempo, a organização realiza discursos de cooperação e de necessidade de trabalho em equipe, gerando um grande paradoxo. Essa discrepância entre competir e cooperar faz surgir, no ambiente de trabalho, movimentos de violência, dentre eles o assédio moral no trabalho. Para Hirigoyen (2002), o assédio moral no trabalho decorre da batalha de forças consequentes do surgimento de novos papéis

\footnotetext{
${ }^{1}$ Endereço para correspondência:

Rua Barão de Melgaço, 369, apto 31 - Real Parque - 05684-030 São Paulo-SP.

E-mail: mcf.martins@uol.com.br

As autoras agradecem o apoio financeiro da CAPES, sob forma de bolsa de Mestrado, à segunda autora.
}

no ambiente organizacional, que demandam um novo perfil profissional.

Mais recentemente, o estudo do assunto tem mobilizado áreas como Psicologia, Medicina, Filosofia, História e Direito, que vêm contribuindo para um debate amplo e interdisciplinar, ampliando o leque de compreensão sobre o fenômeno. A manifestação de danos psíquicos e psicossomáticos decorrentes do trabalho endossa a preocupação da Organização Internacional do Trabalho (OIT) e a Organização Mundial da Saúde (OMS).

Entender e detectar a manifestação do assédio moral não é tarefa fácil, visto que sua violência se traduz muito mais em palavras (ou a ausência delas), gestos e olhares, do que em atos físicos, confundindo até mesmo a própria vítima. Em princípio, é importante compreender que nem toda violência é física. Barreto (2003), Einarsen (2000), Freitas (2007), Heloani, Freitas e Barreto (2008), Guimarães e Rimoli (2006), Hoel, Sparks e Cooper (2001) e Leymann (1996) evidenciam o impacto e o dano gerado pela violência psicológica, não-física, que caracterizam o assédio moral, bastante presente nos contextos organizacionais.

Entende-se por assédio moral um comportamento interpessoal destinado a agredir 
intencionalmente outro empregado no local de trabalho (Aquino \& Lamertz, 2004). No Brasil, Barreto (2003) definiu-o como a exposição repetitiva e prolongada dos trabalhadores a situações de humilhação, vexame e constrangimento ao longo da jornada de trabalho. Essas situações ocorrem comumente em relações hierárquicas autoritárias, negativas, desumanas e desprovidas de ética, provenientes de um ou mais chefes e direcionadas a um subordinado. Elas desestabilizam a vítima, sua relação com o ambiente de trabalho e com a organização.

Apesar de não ser um fenômeno atual, o assédio moral no trabalho não foi sistematicamente explorado até o começo dos anos 80. Relata Leymann (1996), em 1976, que Brodsky referiu-se ao assunto a partir da expressão "the harassed worker", tratando-o como situações de estresse. Leymann aponta, ainda, que ele e Gustavsson começaram a tratar o tema como objeto de pesquisa. Foi de Leymann a denominação mobbing, palavra utilizada na etologia, derivativa de mob, que significa bando, plebe, traduzindo a concepção de algo irritante ou importuno (Hirigoyen, 2002).

Leymann (1990) define assédio moral no trabalho como fenômeno manifestado por violência psicológica extrema, exercida de maneira sistemática e recorrente por uma pessoa ou grupo de pessoas sobre outra pessoa no local de trabalho, cuja ocorrência deve perdurar por um tempo mínimo de seis meses e uma frequência média de duas vezes na semana. Para Leymann, como objetivo do assédio é desestabilizar ou destruir as redes de comunicação da vítima, arrasar sua reputação, atrapalhar a execução de seu trabalho e conseguir enfim que o assediado abandone o local de trabalho faz parte de sua caracterização o uso sistemático, longo e frequente da hostilidade.

Hirigoyen (2002) defende que a violência da agressão independe de sua frequência, ressaltando que determinadas manifestações humilhantes podem desestruturar alguém em menos de seis meses, corroborando sua afirmação. Mas, como se demonstrou neste texto, não existe consenso sobre o conceito.

$\mathrm{Na}$ perspectiva de atores envolvidos no assédio moral, Hirigoyen (2002) expõe duas formas de ocorrência: a horizontal, em que um colega agride outro colega, estando ambos em um mesmo nível hierárquico ou ocupacional; e a vertical, que se subdivide em outras duas - o superior é agredido pelo subordinado, ou o contrário, em que o subordinado é agredido pelo superior. Ansart (2006) nomeia estas subdivisões da forma vertical como assédio ascendente e descendente.
Estudiosos têm explorado os antecedentes do assédio moral no trabalho com o intuito de entender e reduzir potencialmente os seus impactos sobre os indivíduos e as organizações. O fenômeno é multifacetado e multicausal, o que inclui a relação de fatores organizacionais e grupais, não sendo somente justificado por aspectos individuais (Ashforth, 1997; Douglas \& Martinko, 2001; Einarsen, Hoel, Zapf \& Cooper, 2003; Zapf, 1999).

\section{Instrumentos de medida do assédio moral no trabalho}

A revisão de literatura feita para este estudo revelou a carência de instrumentos válidos e fidedignos para a mensuração do fenômeno. Dilek e Aytolan (2008) atribuem a isto a dificuldade em determinar a violência ocorrida no local de trabalho, dificultando ainda mais a abordagem do fenômeno. A maioria dos estudos quantitativos utiliza medidas que não se ajustam aos critérios de construção de instrumentos psicométricos (Soares \& Ferreira, 2006), o que os torna bastante frágeis. Particularmente no Brasil, a maioria dos estudos quantitativos restringe-se aos do tipo epidemiológico (Barreto, 2003; Palácios, Santos, Val \& Pereira, 2008).

Foram localizados na literatura internacional quatro instrumentos para medida do assédio moral no trabalho. Segundo Zapf, Knorz e Kulla (1996), o Leymann Inventory of Psychological Terror - LIPT, de Leymann (1990), é o instrumento de medida de assédio moral no trabalho mais utilizado nos estudos publicados. O LIPT foi construído a partir da identificação clínica e epidemiológica de 45 condutas características do processo de assédio moral e publicado em alemão. O Inventário foi utilizado em estudos realizados em diferentes países em sua forma original ou traduzido e revisto (por exemplo, em González de Rivera \& Rodríguez-Abuín, 2003; Niedl, 1995; Zapf e cols., 1996). Possuía originalmente quatro fatores (Limite da comunicação, Limite do contato social, Desprestígio da pessoa ante os colegas e Descrédito das capacidades profissionais e laborais), que reuniam 45 itens. Informações sobre estudos de índices de fidedignidade dos fatores não constam do artigo de Leyman. Mas dois outros estudos investigaram a fidedignidade dos fatores e testaram sua estrutura empírica: o de Niedl (1995) e o de Zapf e cols. (1996).

Em 1995, Niedl revalidou fatorialmente o LIPT. Sua análise fatorial reteve sete fatores e 45 itens. Foram eles: Ataques à integridade pessoal, Isolamento, Crítica direta e indireta, Sanções através de certas tarefas, Ataque à vida privada, Assédio sexual e Ameaças. A fidedignidade do instrumento foi aferida por meio do alfa de Cronbach, que revelou os 
seguintes valores: $0,93,0,91,083,0,81,0,71,0,71 \mathrm{e}$ 0,63 , respectivamente.

Em 1996, Zapf e colaboradores retestaram a estrutura fatorial do LIPT em duas amostras: uma de 50 e outra de 99 sujeitos, ambas pequenas para o número de itens do inventário. Identificaram uma estrutura semelhante à encontrada por Niedl (1995), de sete fatores, mas retiveram 38 e não 45 itens: Atitudes organizacionais (alfa de Cronbach $=0,86$ ), Isolamento social da vítima (alfa de Cronbach $=0,83$ ), Ataques à vida privada (alfa de Cronbach=0,75), Violência física (alfa de Cronbach=0,69), Agressões verbais (alfa de Cronbach $=0,66$ ), Rumores (alfa de Cronbach $=0,65$ ) e Ataques às crenças e valores da vítima (alfa de Cronbach=0,63). Mas o LIPT ainda carece de confirmação da validade fatorial e alguns de seus fatores permanecem com índices medíocres de fidedignidade aferida pelo alfa de Cronbach. Parece que esses problemas levaram outros autores a tentarem obter uma medida psicometricamente mais adequada do assédio moral no trabalho.

Em 2004, Fidalgo e Piñuel construíram e validaram o Cuestionario Individual sobre Psicoterror, Negación, Estigmatización y Rechazo en Organizaciones Sociales - CISNEROS, composto por 45 itens, cujo objetivo era investigar o estado e as consequências da violência no trabalho. Investigaram suas dimensões por meio da análise multidimensional, que revelou que os itens se reuniam em duas dimensões, denominadas Âmbito da conduta de assédio e Tipo de conduta de assédio. A fidedignidade foi estimada pelo método das metades $(r=0,97)$, tendo os autores dividido aleatoriamente o CISNEROS para compô-las.

Einarsen e Hoel (2001) revisaram o Negative Acts Questionnary - NAQ, construído em 1997 por Einarsen e Raknes (conforme citado por Einarsen \& Hoel, 2001) para medir a exposição percebida ao assédio e à vitimização no trabalho. Validado fatorialmente, o NAQ ficou constituído por 20 itens distribuídos em dois fatores: Assédio moral pessoal e Assédio moral relacionado ao trabalho. Os índices de fidedignidade, calculados pelo alfa de Cronbach, foram, respectivamente, de 0,87 e 0,81 , revelando um instrumento de boas características psicométricas.

Mais recentemente, em 2008, Fornés, Martínez-Abascal e García de la Banda construíram o Cuestionario de Hostigamiento Psicológico en el Trabajo CHPT, para avaliar o assédio moral no trabalho e testaram sua estrutura empírica por meio da análise fatorial. Retiveram 35 itens distribuídos em cinco fatores: Humilhação e rejeição pessoal (alfa de Cronbach $=0,92$ ), Desprestígio profissional (alfa de Cronbach $=0,89)$, Rejeição profissional e violação da intimidade (alfa de Cronbach $=0,84$ ), Isolamento profissional (alfa de Cronbach=0,83) e Degradação profissional (alfa de Cronbach $=0,80$ ).

No Brasil, em 2008, Maciel e Gonçalves testaram a validade do Questionário de Atos Negativos (que denominaram QuAN) partindo do Negative Acts Questionnary, desenvolvido por Einarsen e Raknes (1997). Entretanto, as autoras relatam como indícios de validade os resultados de dois procedimentos. O primeiro deles é a confiabilidade do conjunto dos 22 itens do QuAN (alfa de Cronbach=0,91). Todavia, conforme Nunnally e Bernstein (1995), a consistência interna é condição "necessária, mas não suficiente para a validade de construto" (p. 100). Como segunda prova de validade, Maciel e Gonçalves (2008) calcularam a correlação entre o QuAN e as respostas a uma pergunta aberta feita ao indivíduo ao final do QuAN, que investigava se ele se sentia assediado ou não. Encontraram entre ambos uma correlação $(r=0,49)$ significante, concluindo que este índice representava uma prova de validade de construto. Segundo Anastasi e Urbina (2000), validade de construto é "a extensão em que podemos dizer que o teste mede um construto teórico ou um traço... e a validação de construto requer a acumulação gradual de informação de várias fontes" (p. 117). A utilização de uma única pergunta como critério externo não parece ser prova suficientemente sólida para aferir validade. Mas, apesar das críticas apontadas, a investigação de Maciel e Gonçalves (2008) tem o mérito de submeter um instrumento de medida de assédio à validação no Brasil, além de alertar para a necessidade da disponibilização de instrumentos de medida válidos e confiáveis para a mensuração do fenômeno.

Além das considerações anteriores, é necessário que um instrumento de medida parta de uma conceituação do fenômeno que abranja as várias dimensões consideradas até então, para que possa contribuir com o estudo das relações entre o fenômeno medido e outras variáveis. Assim, o objetivo deste estudo foi adaptar e validar o Cuestionario de Hostigamiento Psicológico en el Trabajo (Fornés e cols., 2008) para uma amostra de trabalhadores brasileiros, pois este instrumento é conceitualmente bastante abrangente. Dessa forma, este estudo justifica-se pela necessidade de um instrumento válido e fidedigno para o contexto brasileiro. Seus resultados poderão contribuir para o estudo deste fenômeno, que urge ser discutido.

\section{Método}

\section{Participantes}

Participaram do estudo 208 trabalhadores, ocupantes de cargos vinculados a um superior hierárquico. Dentre 
eles, constam 135 mulheres $(65 \%)$ e $67(32 \%)$ homens (6 não responderam), com idades variando entre $17 \mathrm{e}$ 61 anos (média de 30 anos, $\mathrm{dp}=$ 9), nível de escolaridade de primeiro grau incompleto à pósgraduação completa, sendo predominante o segundo grau completo (53\%), ocupantes de funções diversas, como as exercidas em administração/escritório (34\%), saúde $\quad(16 \%)$, serviços gerais $(11 \%)$, atendimento/recepção de pessoas $(9 \%)$, policiamento $(7 \%)$, venda (4\%) e licenciatura (4\%).

\section{Procedimentos de adaptação da escala}

Identificados os instrumentos publicados para medida de assédio moral no trabalho, optou-se por adaptar e validar o Cuestionario de Hostigamiento Psicológico en el Trabajo (Fornés e cols., 2008), apesar das críticas apontadas, porque, como o instrumento seria revalidado, esperava-se superar tal problema no decorrer do processo de revalidação. Por outro lado, o questionário de Fornés e cols. (2008) cobre de modo suficiente o conceito. Essa medida é composta por 35 afirmativas distribuídas em cinco fatores (Humilhação e rejeição pessoal, Desprestígio profissional, Rejeição profissional e violação da intimidade, Degradação profissional, e Isolamento profissional), respondidas em escala que varia de $0=$ menos de uma vez ao mês até $5=$ uma ou mais vezes ao dia, a partir da qual se mede a frequência de ocorrência de situações negativas. Há ainda, ao final do questionário, três questões fechadas, respondidas em escala dicotômica (sim ou não), nas quais o respondente identifica se há periodicidade mínima de seis meses para alguma das situações descritas, se foi testemunha de alguma situação descrita e se se sente assediado psicologicamente no trabalho.

Para este trabalho de validação, foi feita a tradução do questionário para a língua portuguesa, decompondo-se os itens com ideias duplas, excluindose aqueles com informações iguais ou que não se adequavam à realidade brasileira e, posteriormente, adequando-se a terminologia à população de trabalhadores e às relações entre superiores e subordinados. Descartaram-se as três questões fechadas finais. Em seguida, o conjunto de itens foi submetido à avaliação de cinco juízes, aos quais foi solicitado que analisassem o conteúdo de cada um e o associasse a cada um dos cinco fatores devidamente descritos. Todos foram classificados conforme a alocação original de itens por fator do estudo de Fornés e cols. (2008), tendo sido mantidos. A compreensão dos itens e a adequação da redação foram testadas com alguns representantes do menor nível de escolaridade (ensino fundamental) da amostra com a qual se pretendia trabalhar. Esse procedimento revelou a clareza e a compreensão dos itens por parte da população-alvo.

Em razão desse procedimento, a versão final para aplicação ficou composta por 36 itens. Como os estudos localizados na revisão bibliográfica apontavam dois aspectos importantes envolvidos na definição do assédio moral no trabalho, percepção da frequência de ocorrência do assédio, e sentimento que as diversas situações descritas causam nos trabalhadores, diferentemente do original, decidiu-se preparar questionários com os mesmos itens, mas com escalas de respostas diferentes, uma destinada a avaliar a percepção da frequência de ocorrência do assédio e a outra a humilhação sentida diante das situações percebidas. Assim, da escala de Fornés e cols. (2008), derivaram-se duas novas: uma designada a medir a percepção da frequência de ocorrência do assédio e outra para avaliar o sentimento sobre o que se passou. A investigação de dados sociodemográficos (idade, sexo, escolaridade e cargo) foi feita de modo a caracterizar os participantes e constava ao final do questionário.

\section{Procedimentos de coleta e análise de dados}

Os participantes deste estudo foram amostrados da população de trabalhadores de uma cidade de médio porte (600 mil habitantes) do interior de Minas Gerais, sendo abordados em pontos estratégicos de fluxo de pedestres. Os passantes foram questionados individualmente para verificação dos critérios para inclusão na amostra (escolaridade e subordinação a um superior, já que o objetivo era avaliar assédio moral vertical descendente) e do interesse em participar da pesquisa. Foram esclarecidos os objetivos do estudo e o anonimato das respostas; explicou-se ainda a necessidade de ambos, pesquisador e participantes, assinarem o Termo de Concordância Livre e Esclarecido para atender à Resolução 196 do Conselho Nacional de Saúde e foi solicitada a colaboração de cada um. Aos que assentiam, era entregue o instrumento contendo os questionários de assédio moral no trabalho e $\mathrm{O}$ de dados sociodemográficos. Seguia-se o preenchimento pelos próprios participantes. A pesquisadora aguardava e recolhia. A amostra foi, portanto, voluntária. O trabalho foi aprovado pelo Comitê de Ética em Pesquisa de uma Universidade Federal.

As respostas foram codificadas numa única planilha do programa Statistic Package of Social Science (versão 15.0). Os dados coletados foram examinados quanto à normalidade, colinearidade e distribuição de dados extremos. A fatorabilidade dos dados foi testada pelo índice de Kaiser-Meyer-Olkin, pelo teste de esferecidade de Bartlett, além de ter-se atentado para o determinante da matriz de correlações. Depois disso, 
os dados foram submetidos a análises dos componentes principais (PC) e à fatoração dos eixos principais (PAF). A fidedignidade dos fatores foi estimada pelo cálculo dos alfas de Cronbach. As escalas foram analisadas separadamente.

\section{Resultados}

As escalas receberam as denominações Escala de Percepção do Assédio Moral no Trabalho (EPAMT) e Escala de Impacto Afetivo do Assédio Moral no Trabalho (EIA-AMT). Detalhes dos resultados que revelaram a estrutura fatorial de ambas são relatados a seguir.

\section{Escala de Percepção do Assédio Moral no Trabalho (EP-} AMT)

Os resultados do teste de Kaiser-Meyer-Olkin $(\mathrm{KMO}=0,89)$, considerado admirável por Hair Jr., Anderson, Tatham e Black (2005), do teste de esferecidade de Bartlett $\left(\chi^{2}=4587,401 ; \mathrm{p}<0,001\right)$ e o determinante da matriz de correlações (6,38E-011) demonstraram a adequação da amostra para análise fatorial. A partir da análise dos componentes principais, estimou-se o número de componentes que, inicialmente, correspondiam a oito, cada qual com valores próprios iguais a ou maiores que 1,0 e cargas fatoriais iguais a ou maiores que 0,30 que explicavam $68 \%$ da variância total. Contudo, o scree plot demonstrou a existência de, no máximo, seis componentes.

Posteriormente, os dados foram submetidos à fatoração dos eixos principais com rotação oblimin. A matriz de correlação entre os fatores revelou claramente dois agrupamentos: o fator 1 isolava-se dos outros, enquanto a maioria dos demais, mantinha entre si índices de correlação significantes. Isso sustentou a rotação oblimin, mas apontou certa independência entre os dois agrupamentos.

Indicações teóricas e evidências da estrutura fatorial do Cuestionario de Hostigamiento Psicológico en el Trabajo (Fornés \& cols., 2008) em cinco fatores sustentaram a solicitação da extração de cinco fatores. Os resultados revelaram que os itens de um fator referiam-se a aspectos pessoais, enquanto os dos outros quatro aproximavam-se conceitualmente de aspectos profissionais, o que havia sido evidenciado pelas correlações significantes entre eles demonstradas na primeira extração. Esses resultados evidenciam a presença de fatores de ordem superior (Pasquali, 2006). Em decorrência dessa identificação, solicitou-se a extração de dois fatores, mas nessa fase foram incluídos somente os 24 itens componentes dos fatores que possuíam valores próprios maiores que ou iguais a um. Ambos explicaram 48\% da variância total.

Os dois fatores reuniram o conjunto de 24 itens. A amostra revelou índices adequados de fatorabilidade: índice de Kaiser-Meyer-Olkin (KMO) igual a 0,89 e Teste de Esferecidade de Bartlett significante $\left(\chi^{2}=2827,651, \mathrm{p}<0,001\right)$. O primeiro fator, denominado assédio profissional, explicou $40 \%$ da variância total da percepção do assédio moral no trabalho (ver Tabela 1), teve alfa de Cronbach de 0,91, e reuniu 14 itens, tais como: "seu chefe te ignorou em questões ou decisões que dizem respeito à sua área de trabalho" e "seu chefe não respeitou seu conhecimento ou sua experiência de trabalho". O segundo fator, denominado assédio pessoal, explicou $8 \%$ da variância total explicada, revelou alfa de Cronbach de 0,85, e reuniu dez itens com conteúdo como: "seu chefe falou coisas que prejudicaram sua imagem" e "seu chefe imitou seus gestos, palavras ou comportamentos em tons humilhantes ou de gozação" (Tabela 1).

\section{Escala de Impacto Afetivo do Assédio Moral no Trabalho (ELA-AMT) \\ O resultado dos testes de fatorabilidade da} amostra foram também muito bons para esta subamostra $(\mathrm{KMO}=0,83$, Teste de Esferecidade de Bartlett: $\chi^{2}=4231,831 ; \quad \mathrm{p}<0,001 ;$ determinante da matriz de correlações $=2,17 \mathrm{E}-010$ ), o que demonstrou sua adequação para análise fatorial. Foi nove o número de componentes estimados pela análise dos componentes principais com valores próprios iguais a ou maiores que um e cargas fatoriais iguais a ou maiores que 0,30 . Os nove fatores explicaram $68 \%$ da variância total. Entretanto, o scree plot apontou a existência de, no máximo, cinco componentes.

Posteriormente, os fatores foram extraídos pelo método dos eixos principais (PAF) com rotação oblimin. A matriz de correlação entre os fatores revelou dois agrupamentos de fatores: o cinco isolavase dos outros porque possuía apenas uma correlação significante com os demais. Os fatores oito e nove não se sustentaram porque seus itens eram, em sua maioria, complexos (dividiam cargas em mais de um fator). Analisando os conteúdos dos itens que formavam os fatores restantes, via-se agrupamento semelhante ao identificado na escala de percepção do assédio. Isto sustentou a rotação oblimin, mas apontou inicialmente certa discriminação entre os dois agrupamentos, embora ambos fossem significantemente correlacionados $(r=0,64, \mathrm{p}<0,01)$ entre si. 
Tabela 1. Características psicométricas dos fatores de percepção do assédio moral

\begin{tabular}{|c|c|c|c|}
\hline Fatores & Item & Carga & Comunalidade \\
\hline \multirow{14}{*}{ 1: profissional } & 1 & 0,54 & 0,48 \\
\hline & 3 & 0,52 & 0,39 \\
\hline & 9 & 0,47 & 0,30 \\
\hline & 10 & 0,81 & 0,70 \\
\hline & 13 & 0,53 & 0,52 \\
\hline & 15 & 0,73 & 0,64 \\
\hline & 21 & 0,53 & 0,24 \\
\hline & 24 & 0,52 & 0,27 \\
\hline & 25 & 0,64 & 0,50 \\
\hline & 26 & 0,83 & 0,56 \\
\hline & 27 & 0,66 & 0,49 \\
\hline & 28 & 0,42 & 0,14 \\
\hline & 31 & 0,47 & 0,59 \\
\hline & 35 & 0,80 & 0,64 \\
\hline$\alpha=0,91$ & \multicolumn{3}{|c|}{ variância explicada $=40 \%$} \\
\hline \multirow{10}{*}{ 2: pessoal } & 6 & 0,30 & 0,26 \\
\hline & 8 & 0,49 & 0,43 \\
\hline & 11 & 0,81 & 0,58 \\
\hline & 12 & 0,82 & 0,68 \\
\hline & 18 & 0,51 & 0,36 \\
\hline & 19 & 0,38 & 0,36 \\
\hline & 23 & 0,61 & 0,42 \\
\hline & 29 & 0,61 & 0,37 \\
\hline & 30 & 0,71 & 0,42 \\
\hline & 36 & 0,35 & 0,15 \\
\hline$\alpha=0,85$ & & explicas & \\
\hline
\end{tabular}

Processo semelhante ao da escala de percepção ocorreu com a análise de dados desta escala, donde cinco fatores teóricos foram mantidos. A partir das evidências desvendadas pela matriz de correlações entre os fatores percebeu-se que dois agrupamentos se revelavam, o que indicava a existência de uma estrutura superior, de segunda ordem. Solicitou-se, então, a extração de dois fatores, buscando identificar a existência dos fatores profissional e pessoal, revelados na escala de percepção do assédio. Nessa extração foram incluídos os 19 itens componentes dos nove fatores retidos na extração anterior. Os dois fatores reuniram os 19 itens. A amostra também se mostrou fatorável (KMO=0,81; Teste de Esferecidade de Bartlett: $\chi^{2}=1803,281, \mathrm{p}<0,001$, determinante da matriz $=2,17 \mathrm{E}$ 010) e os resultados confirmaram a reunião dos itens em dois fatores de ordem superior.

Entretanto, pode-se observar que os conteúdos dos itens dos dois fatores eram muito semelhantes, além de já existir indício de alta correlação entre ambos. Esses resultados serviram como apontamento para nova extração com base nos itens desses fatores, na qual foi forçado um só fator. Resultados revelaram escala composta por 13 itens, com índice de consistência interna de 0,85 (Tabela 2).

\section{Discussão}

A ausência de instrumento validado no Brasil para avaliar assédio moral no ambiente de trabalho, apontou a necessidade deste estudo. A adoção do Cuestionario de Hostigamiento Psicológico en el Trabajo (Fornés \& cols., 2008) como ponto de partida para a validação deu-se em razão das críticas apontadas por seus autores aos instrumentos de Einarsen e Raknes (1997), Fidalgo e Piñuel (2004), González de Rivera e Rodríguez-Abuín (2003), Leymann (1990), Niedl (1995) e Zapf e cols. (1996). Além disso, o conteúdo de seus itens e sua composição fatorial representa as discussões teóricas identificadas na literatura. Suas características psicométricas acenavam uma possibilidade de sucesso para a validação no Brasil. 
Contudo, a rotação varimax utilizada pelos autores era questionável, considerando que os fatores componentes da escala eram semanticamente semelhantes e que a literatura revelava uma relação conceitualmente aproximada entre os aspectos pessoal e profissional. Essas considerações e observações apontam para a opção de uma rotação oblimin como a mais adequada para fatores interdependentes (Nunnally
\& Bernstein, 1995), confirmada nas primeiras extrações pelos índices de correlação entre os fatores. O resultado deste estudo culminou em dois instrumentos, válidos e fidedignos, para atender à necessidade de detectar a frequência da percepção do assédio moral (vertical descendente) no trabalho, e o impacto afetivo desses atos hostis percebidos nos trabalhadores.

Tabela 2. Características psicométricas da Escala de Impacto Afetivo do Assédio Moral

\begin{tabular}{ccc}
\hline Item & Carga & Comunalidade \\
\hline 3 & 0,69 & 0,55 \\
7 & 0,48 & 0,56 \\
9 & 0,43 & 0,47 \\
10 & 0,71 & 0,56 \\
18 & 0,57 & 0,52 \\
19 & 0,65 & 0,60 \\
22 & 0,66 & 0,48 \\
24 & 0,43 & 0,36 \\
27 & 0,67 & 0,60 \\
28 & 0,30 & 0,34 \\
30 & 0,52 & 0,54 \\
33 & 0,43 & 0,35 \\
36 & 0,50 & 0,46 \\
\hline
\end{tabular}

A escala de percepção foi nomeada Escala de Percepção do Assédio Moral no Trabalho (EP-AMT), apresentou alfa de Cronbach geral de 0,93 e explicou $48 \%$ do total da variância. A escala relativa aos graus de humilhação que o indivíduo sente ante as situações vivenciadas foi denominada de Escala de Impacto Afetivo do Assédio Moral no Trabalho (EIA-AMT), revelou alfa de 0,85 e explicou $46 \%$ do total da variância.

Cada escala ficou composta por um número diferente de itens, porque, a partir das análises fatoriais, alguns itens permaneceram alocados em fatores de segunda ordem semelhantes em ambas, mas outros itens foram excluídos de uma e não de outra, ou de ambas (tabelas I e II). A despeito da expectativa com relação aos fatores semelhantes para ambas as escalas, apenas na de Percepção de Assédio Moral identificouse a divisão entre fatores profissional e pessoal, já que a Escala de Impacto Afetivo reteve os itens em fator único, o que parece justificar-se porque, nesse caso, o sentimento de humilhação parece independer do foco do assediador (no âmbito profissional ou pessoal da vítima).

A carência de instrumentos de medida de assédio moral no trabalho no Brasil apontava a necessidade de disponibilizar instrumentos válidos $\mathrm{e}$ confiáveis que pudessem mensurar o fenômeno. Mensurá-lo com instrumentos de boas características psicométricas é importante para enriquecer a teoria e a discussão do fenômeno e colabora para com a ampliação dos estudos sobre o assunto. A proximidade do tema a outras áreas, como Medicina (Barreto, 2003), História (Seixas \& Bresciani, 2006) e Direito (Rezende, 2008), e as discussões sobre o assédio moral que aî despontam reforçam a necessidade de articular os estudos sobre o assunto.

\section{Conclusão}

A distinção aqui proposta e confirmada entre percepção e sentimento (impacto afetivo) na conceituação do assédio moral é nova no Brasil, e ainda não possui força nos estudos estrangeiros. Apesar de estes dois aspectos aparecerem em algumas proposições teóricas como em Coyne, Craig e Chong (2004), o enfoque na caracterização do assédio moral tem sido na frequência e na periodicidade de ocorrência dos atos hostis (Hirigoyen, 2002; Leymann, 1990), permanecendo fora de foco o sentimento implícito nas consequências danosas que a vítima de assédio sofre. Maciel e Gonçalves (2008), ao validarem o QuAN, que partiu do NAQ (Einarsen \& Raknes, 1997), chegaram a referir-se a essa possível 
diferenciação quando, ao final do QuAN, alocam uma única pergunta acerca da possível humilhação sentida diante das ações de assédio percebidas.

Einarsen e Hoel (2001) relatam um estudo com o NAQ no qual os autores o submeteram à análise fatorial com rotação varimax. A estrutura encontrada na Escala de Percepção de Assédio relatada neste artigo corrobora achados dessa investigação, pois reteve igualmente dois fatores, denominados assédio pessoal, composto por 12 itens relacionados à exposição a fofocas, insultos persistentes, provocações excessivas e críticas constantes, e assédio relacionado ao trabalho, composto por oito itens referentes ao estabelecimento de prazos irreais, sobrecarga de trabalho, vigilância excessiva e boicote de informações, com índices de fidedignidade de 0,87 e 0,81 .

A identificação de duas estruturas diversas, uma para a percepção do assédio e outra para o impacto afetivo que provoca, parece justificar-se também teoricamente. A importância de se considerar o papel da percepção como parte do construto de assédio moral advém da consideração de que as pessoas percebem o que precisam ou esperam perceber. Assim, a percepção funciona como um filtro seletivo, de modo que a realidade organizacional que se estuda só pode ser conhecida através da percepção daqueles que dela fazem parte. Mas perceber não significa afetar emocionalmente, conforme demonstram estudos sobre o assunto (Barreto, 2003; Chappel \& Di-Martino, 1999; Einarsen, 2000; Hoel, Sparks \& Cooper, 2001; Leymann, 1996; Piñuel y Zabala, 2003). A identificação de duas estruturas diferentes corrobora estas ponderações.

Outra consideração importante a fazer é a de que os estudos que se utilizam de métodos qualitativos para a identificação do assédio moral no trabalho fornecem evidências que também apoiam a estrutura empírica identificada neste estudo por análise fatorial. Por exemplo, O'Connell, Calvert e Watson (2007), em estudo realizado na Irlanda com 3.579 trabalhadores, encontraram que a natureza do fenômeno relatada pelos participantes por meio de relato livre referia-se a exclusão, abuso verbal, abuso físico, tratamento desfavorável, designação de tarefas pouco condizentes com a competência do trabalhador, humilhação, vigilância excessiva do trabalho dos assediados, ameaças, intimidação, boicote de informações e atribuição de culpa por acontecimentos fora do controle do empregado.

Estudos brasileiros de abordagem qualitativa também revelam que, na linguagem dos trabalhadores assediados, o fenômeno é constituído por pressão excessiva, sob forma de cobranças que não consideram a realidade do trabalho (Barreto, 2005; Soboll, 2008), de isolamento, manipulação de informações, incentivo à competitividade selvagem, desrespeito, humilhação, designação de tarefas abaixo da competência, agressões verbais, isolamento e relação abusiva de poder (Soboll, 2008). Soares (2006), em estudo sobre assédio moral no trabalho numa instituição financeira, no qual utilizou observação participante, identificou nos relatos dos trabalhadores assediados três categorias de práticas assediadoras: as que visam à desestabilização do empregado, as difamadoras e as de isolamento. Esses achados, embora tenham sido obtidos por metodologia diversa, revelam certa estabilidade na caracterização do assédio.

A percepção da frequência por parte dos trabalhadores de uma organização dá indícios de ocorrerem ou não comportamentos de assédio moral no ambiente de trabalho, e mensura com qual frequência eles são manifestados (no caso específico dos presentes instrumentos, no sentido dos supervisores para os subordinados). Mas o impacto afetivo sofrido pelos trabalhadores que vivenciam ou observam tais comportamentos indicaria quem, realmente, pode ser considerado assediado moralmente. Traduzindo para a realidade prática, a frequência de comportamentos de assédio permite distinguir conflitos passageiros daqueles intencionalmente repetidos, e proporciona a tomada de consciência por parte da organização sobre o que e quanto ocorre.

A percepção de hostilidades indica a presença de ações negativas que podem ou não afetar os trabalhadores, a depender do impacto afetivo que provocam. Para identificar a percepção da existência do assédio e seu impacto nos trabalhadores, as duas escalas resultantes deste estudo permitem à organização tomar medidas contra aqueles que assediam para evitar a deterioração do ambiente de trabalho.

Este estudo teve limitações. A amostra voluntária talvez seja a maior delas. Pode ser que pessoas realmente assediadas no trabalho não tenham sido localizadas ou não tenham desejado participar do estudo por estarem muito sensibilizadas emocionalmente ou por terem medo de se expor. Outra limitação refere-se ao fato de o estudo ter sido realizado com participantes de um único estado brasileiro. Esses dois aspectos fizeram com que a amostra não tenha representado os trabalhadores brasileiros. Por isso, suas conclusões limitam-se à percepção e aos impactos afetivos sentidos pelos trabalhadores que dele participaram.

Além disso, este estudo poderia ter incluído intencionalmente pessoas assediadas moralmente no trabalho buscando-as em tribunais trabalhistas que 
recebem suas queixas e em locais de apoio que atendem essas vítimas. Ainda assim, não se teria alcançado aqueles trabalhadores assediados que não buscam ajuda. Reconhece-se que isso também limita os achados desta investigação, mas o tema é delicado e de difícil acesso, pois pessoas assediadas sentem-se acuadas, amedrontadas, humilhadas e, para se defenderem, fecham-se, muitas vezes não buscando ajuda legal ou profissional.

Investigações como a de O'Connell, Calvert e Watson (2007) com trabalhadores irlandeses revelam que a incidência de assédio moral no trabalho no setor público é $40 \%$ maior do que no setor privado. Isso remete à outra limitação deste estudo: a de não ter buscado intencionalmente respondentes em empresas desses dois tipos.

Mas se entende que este estudo forneceu dois instrumentos para diagnóstico que podem facilitar futuras investigações. Não se tem a intenção de que as escalas aqui produzidas substituam a interação entre psicólogos e outros profissionais de ajuda e vítimas de assédio moral no trabalho. $\mathrm{O}$ que se pretendeu foi oferecer ferramentas válidas e confiáveis que abreviem o tempo de diagnóstico e que indiquem a presença de assédio e o quanto ele atinge emocionalmente o trabalhador. Entende-se que este objetivo foi atingido.

Além disso, segundo relata Salin (2001), os métodos quantitativos para a identificação do assédio moral no trabalho captam mais facilmente a ocorrência do fenômeno. Relata o autor que, quando se utilizam questionários ou escalas, os respondentes indicam o triplo de percepções de ocorrências de assédio do que quando as tem que descrever verbalmente ou por escrito.

Sugere-se que novos estudos sejam desenvolvidos para testar a estabilidade das estruturas fatoriais encontradas nas duas escalas relatadas neste estudo em novas amostras e que elas provenham de diversas regiões geopolíticas brasileiras. Entende-se, ainda, que estudos que visem à padronização de ambas as escalas sejam úteis. Além disso, é necessário avançar nos estudos de validação com o objetivo de testar as estruturas fatoriais aqui identificadas com técnicas mais exigentes, como a análise fatorial confirmatória.

\section{Referências}

Anastasi, A. \& Urbina, S. (2000). Testagem psicológica. Porto Alegre: Artmed.

Ansart, P. (2006). Os assédios políticos. Em J. Seixas \& M. S. Bresciani (Orgs.). Assédio moral: desafios políticos, considerações sociais, incertezas jurídicas (pp. 125-137). Uberlândia, MG: EDUFU.
Aquino, K. \& Lamertz, K. (2004). A relational model of workplace victimization: social roles and patterns of victimization in dyadic relationships. Journal of Applied Psychology, 89(6), 1023-1034.

Ashforth, B. (1997). Petty tyranny in organizations: a preliminary examination of antecedents and consequences. Canadian Journal of Administrative Sciences, 14(2), 126-140.

Barreto, M. M. S. (2003). Violência, saúde e trabalho: uma jornada de humilhaçôes. São Paulo: EDUC.

Barreto, M. M. S. (2005). Assédio moral: a violência sutil análise epidemiológica e psicossocial no trabalho no Brasil. (Tese de doutorado). São Paulo: Pontifícia Universidade Católica de São Paulo.

Chappel, D. \& Di-Martino, V. (1999). Violence at work. Asian-Pacific Newsletter on Occupational Health and Safety, 6(1), 1-7.

Coyne, I., Craig, J. \& Chong, P. S-L. (2004). Workplace bullying in a group context. British Journal of Guidance \& Counselling, 32(3), 301-317.

Dilek, Y. \& Aytolan, Y. (2008). Development and psychometric evaluation of workplace psychologically violent behaviours instrument. Journal of Clinical Nursing, 17, 1361-1370.

Douglas, S. \& Martinko, M. (2001). Exploring the role of individual differences in the prediction of workplace aggression. Journal of Applied Psychology, 86(4), 547-559.

Einarsen, S. (2000). Harassment and bullying at work: a review of the scandinavian approach. Aggression and Violent Behavior, 5(4), 379-401.

Einarsen, S. \& Raknes, B. I. (1997). Harassment in the workplace and the victimization of men. Violence and Victims, 12, 247-263.

Einarsen, S. \& Hoel, H. (2001, maio). The Negative Acts Questionnaire: development, validation and revision of a measure of bullying at work. Trabalho apresentado no $10^{\circ}$ European Congress on Work and Organizational Psychology, Prague. Obtido em 17/08/2008 da world wide web: http://www.bullying.no/content/naq/The $\% 20 \mathrm{Ne}$ gative $\% 20$ Acts $\% 20$ Questionnaire.pdf.

Einarsen, S., Hoel, H., Zapf, D. \& Cooper, C. (2003). The concept of bullying at work: the European tradition. Em S. Einarsen, H. Hoel, D. Zapf \& C. Cooper (Orgs.). Bullying and emotional abuse in the workplace: International perspectives in research and practice (pp. 1-30). London, England: Taylor \& Francis. 
Fidalgo, A. M. \& Piñuel, I. (2004). La escala Cisneros como herramienta de valoración del mobbing. Psicothema, 16(4), 615-624.

Fornés, J., Martínez-Abascal, M. A. \& García de la Banda, G. (2008). Análisis factorial del cuestionario de hostigamiento psicológico en el trabajo en profesionales de enfermaria. Internacional Journal of Clinical and Health Psychology, 8(1), 267283.

Freitas, M. E. (2007). Quem paga a conta do assédio moral no trabalho? RAE eletrônica, 6(1). Obtido em 27.10.2010 do SciELO (Scientific Electronic Library Online): http://www.scielo.br/.

González de Rivera, J. L. \& Rodríguez-Abuín, M. (2003). Cuestionario de estratégias de acoso psicológico: el LIPT-60 (Leymann Inventory of Psychological Terrorization) en versión española. Psiquis, 24(2), 59-69.

Guimarães, L. A. M. \& Rimoli, A. O. (2006). "Mobbing" (assédio psicológico) no trabalho: uma síndrome psicossocial multidimensional. Psicologia: Teoria e Pesquisa, 22(2), 183-192.

Hair, J. F., Jr., Anderson, R. E., Tatham, R. L. \& Black, W. C. (2005). Análise multivariada de dados (5a ed.). Porto Alegre: Bookman.

Heloani, R. (2004). Assédio moral: um ensaio sobre a expropriação da dignidade no trabalho. RAEeletrônica, 3(1). Obtido em 17/04/2008 do SciELO (Scientific Electronic Library Online): http://www.scielo.br/.

Heloani, J. R., Freitas, M. E. \& Barreto, M. (2008). Assédio moral no trabalho. São Paulo: Cencage.

Hirigoyen, M. F. (2002). Assédio moral: a violência perversa no cotidiano (M. H. Kühner, Trad.). Rio de Janeiro: Bertrand Brasil (Trabalho original publicado em 1998).

Hoel, H., Sparks, K. \& Cooper, C. L. (2001). The cost of violence/stress at work and the benefits of a violence/stressfree working environment. Geneva: International Labour Organization. Obtido em 26/07/2008 do ILO (International Labour Organization): http://www.ilo.org/public/english/protection/sa fework/whpwb/econo/ costs.pdf .

Leymann, H. (1990). Mobbing and psychological terror at workplaces. Violence and Victims, 5(2), 119-126.

Leymann, H. (1996). The content and development of mobbing at work. European Journal of Work and Organizational Psychology, 5(2), 165-184.
Maciel, R. H. \& Gonçalves, R. C. (2008). Pesquisando o assédio moral: a questão do método e a validação do Negative Acts Questionnary (NAQ) para o Brasil. Em L. A. P. Soboll (Org.). Violência psicológica e assédio moral no trabalho: pesquisas brasileiras (pp. 167-185). São Paulo: Casa do Psicólogo.

Niedl, K. (1995). Mobbing/bullying at the work place. München: Rainer Hampp Verlag.

Nunnally, J. C. \& Bernstein, I. J. (1995). Teoría psicométrica. Mexico: McGraw-Hill.

O'Connell, P. J., Calvert, E. \& Watson, D. (2007). Bullying in the workplace: survey reports, 2007. Dublin: Department of Enterprise, Trade and Employment. Obtido em 21/05/2011 do ESRI (Economic and Social Research Institute) http://www.esri.ie/UserFiles/publications/20070 321104635/BKMNEXT094.pdf.

Palácios, M., Santos, M. L., Val, M. B. \& Pereira, B. B. (2008). Violência no trabalho no setor de saúde: um estudo epidemiológico. Em L. A. P. Soboll (Org.). Violência psicológica e assédio moral no trabalho: pesquisas brasileiras (pp. 247-270). São Paulo: Casa do Psicólogo.

Pasquali, L. (2006). Análise fatorial para psicólogos. Brasília, DF: LABPAM.

Piñuel y Zabala, I. (2003). Mobbing: como sobreviver ao assédio psicológico no trabalho. São Paulo: Loyola.

Rezende, L. O. (2008). Revisitando os elementos estruturais do assédio moral: um caminho metodológico necessário para a correta compreensão do tema no âmbito jurídico. Em L. A. P. Soboll (Org.). Violência psicológica e assédio moral no trabalho: pesquisas brasileiras (pp. 57-73). São Paulo: Casa do Psicólogo.

Salin, D. (2001). Prevalence and forms of bullying among business professionals: a comparison of two different strategies for measuring bullying. European Journal of Work and Organizational Psychology, 10(4), 425-441.

Seixas, J. \& Bresciani, M. S. (Orgs.). (2006). Assédio moral: Desafios políticos, consideraçẽes sociais, incertezas jurídicas. Uberlândia, MG: EDUFU.

Soares, L. Q. (2006). Assédio moral no trabalho e interações socioprofissionais: "on você interage do jeito deles ou vai ser bumilhado até não agüentar mais". (Dissertação de mestrado). Brasília: Universidade de Brasília, Distrito Federal, Brasil. 
Soares, L. Q. \& Ferreira, M. C. (2006). Pesquisa participante como opção metodológica para a investigação de práticas de assédio moral no trabalho. Revista Psicologia: Organizações e Trabalho, 6(2). Obtido em 15/06/2008 da world wide web: http://www.periodicos.ufsc.br/index.php/rpot.

Soboll, L. A. P. (2008). Assédio moral no Brasil: a ampliação conceitual e suas repercussões. Em L. A. P. Soboll (Org.). Violência psicológica e assédio moral no trabalho: pesquisas brasileiras (pp. 23-65). São Paulo: Casa do Psicólogo.

Zapf, D. (1999). Organizational, work group related and personal causes of mobbing/bullying at work. International Journal of Manpower, 20(1/2), 70-85.
Zapf, D., Knorz, C. \& Kulla, M. (1996). On the relationship between mobbing factors, and job content, social work environment and health outcomes. European Journal of Work and Organizational Psychology, 5(2), 215-237.

Sobre as autoras:

Maria do Carmo Fernandes Martins é psicóloga pela Universidade de São Paulo (1977), mestre (1984), doutora (1999) em Psicologia pela Universidade de Brasília e professora titular do Programa de Mestrado em Psicologia da Saúde da Universidade Metodista de São Paulo.

Ana Maria Souto Ferraz é graduada (2004) e mestre em Psicologia pela Universidade Federal de Uberlândia (2010). 